\title{
Design, validation and implementation of the Post- Acute (long) COVID-19 Quality of Life (PAC-19QoL) instrument in the PAC-19QoLReg patient registry
}

Ravi Jandhyala ( $\sim$ ravi.jandhyala@kcl.ac.uk)

\section{Research}

Keywords: COVID-19, Public Health, Quality of Life, Statistics \& Research Methods

Posted Date: March 2nd, 2021

DOl: https://doi.org/10.21203/rs.3.rs-255825/v1

License: (1) (1) This work is licensed under a Creative Commons Attribution 4.0 International License. Read Full License 


\section{Abstract \\ Background}

To design, validate and implement a Post-Acute (long) COVID-19 disease-specific quality of life instrument, (the PAC-19QoL), in a dedicated patient registry, PAC-19QoLReg, to observe changes in quaQoL over a 12month period.

\section{Methods}

The Jandhyala Method was used to identify indicators of long COVID quality of life. The resulting PAC19QoL was validated with a control group of unaffected participants and finally implemented in the dedicated PAC-19QoLReg.

\section{Participants}

: 15 participants suffering from long COVID, who have been positively diagnosed with COVID-19, either via diagnostic or antibody tests and a validation control group of 16 healthy participants who have not suffered from COVID-19.

\section{Main Outcome measures:}

Indicators submitted by participants with long COVID that address the specific impact of the illness in their quality of life.

\section{Results}

Forty-four Quality of Life Indicators (QoLI) across four domains - psychological, physical, emotional and work-related - were agreed by the participants with long COVID to be relevant for the assessment of their quality of life $(\mathrm{Cl}>0.5)$. The validation stage identified 35/44 QoLls that differentiated between the two groups, with a statistically significant difference between the mean QoLI Likert Scores $(P<0.05)$.

\section{Conclusions}

The PAC-19QoL instrument and PAC-19QoLReg prospective observational cohort clinical study will enable an understanding of disease progression, on and off treatment, on the quality of life of patients with long COVID beyond simple symptomatology.

\section{Trial registration:}




\section{Background}

From December 2019 onwards, a novel coronavirus (SARS-CoV-2) spread worldwide. In March 2020 the World Health Organization classified it as a pandemic $[1,2]$. The resulting disease from infection with SARS-CoV-2, termed COVID-19, commonly presents in adults as a typical infection of the upper respiratory tract. It ranges from mild to moderate fever, cough and fatigue [3, 4]. In severe cases, pneumonia may develop ( $15 \%$ of cases), whilst an estimated $5 \%$ of COVID-19 patients suffer from acute respiratory distress syndrome (ARDS), septic shock and/or multiple organ failure $[5,6]$. Furthermore, it is anticipated that COVID-19 may have a major impact on physical, cognitive, mental and social health status, even in patients with mild disease presentation [7].

Although the disease is often acute, one in ten patients can continue to be affected for weeks or months [6]. This so-called "long COVID" can result in extreme fatigue, muscle and joint pain, breathlessness, heart palpitations, loss or alteration of the sense of taste and smell, gastrointestinal distress and problems with attention, memory and cognition [6]. In a continued pandemic state, this is likely to contribute significantly to global morbidity and mortality. However, the majority of COVID-19 research has been focussed on the pathogenesis of SARS-CoV-2 and therapeutic strategies, such as vaccines or antiviral drugs [8]. Consequently, there is a lack of formal evidence of any long COVID impact on both the health and quality of life of affected individuals. This represents an important evidence gap [8].

Current tools being developed, such as a clinician facing prognostic communication tool with COVID-19 and critical illnesses [9], appear to be clinician-focused. As such, they fail to address the potential impact of COVID-19 on patients' lives, beyond its symptoms. Furthermore, these tools are not sufficient to capture QoL, as they lack the sensitivity to capture the often complex and multi-dimensional nature of QoL and its changes [10]. The same is true of non-disease-specific QoL instruments being used in preference to disease-specific ones [11].

The absence of a long COVID specific QoL instrument justifies the development of one to complete the understanding of the disease phenotype. Such a development may represent a meaningful patient-centric exercise.

As with other diseases, for one reason or another, the majority of this disease population lie beyond the reach of a clinical trial. However, researching this real-world population continues to be of critical importance to a range of interested parties. This includes regulators, payors and prescribe. Their vehicle of choice is the patient registry or observational cohort clinical study of a prospective and/or retrospective type [12].

To meet this need, this research reports the design, creation and validation of the Post-Acute COVID-19 Quality of Life (PAC-19QoL) instrument for the assessment of individuals with long COVID (IRAS 288729 Bristol SW REC) and its subsequent inclusion as the core dataset in the associated PAC-19QoLReg patient 
registry (ClinicalTrials.gov Identifier: NCT04586413). This patient registry is currently recruiting participants with a clinical diagnosis of long COVID irrespective of test confirmation, for a 12-month follow-up period.

It is hoped that both the PAC-19QoL and PAC-19QoLReg can complement existing tools and ongoing initiatives by researching this important aspect of a debilitating emerging disease. This will be achieved by using a bespoke assessment instrument with the ultimate goal of informing management decisions and improving patient outcomes.

\section{Methods}

\section{Study Participants}

Recruitment took place in December 2020 from adverts placed on social media sites, informal online support groups and snowballing via recruited subjects promoting the study in their own networks of long COVID sufferers.

A total of 15 participants, who had either a diagnostic or antibody test confirmation for SARS-COV-2 and were still suffering from post-acute symptoms of COVID-19, were recruited to the study group. To validate the process, 16 healthy volunteers were recruited.

\section{Sample size}

The sample size calculation was informed by the need to both achieve saturation of PAC-19QoL indicators and assess the degree to which each indicator differentiated between the disease and non-disease state. Previous experience with the Jandhyala Method, predicted saturation of unique indicators at a minimum target sample size of 10 with an upper limit of 20. For validation, using a univariate approach, an indicator was deemed to differentiate between the two groups if the prevalence of the indicator was $>50 \%$ in one group than the other. A minimum sample size of 15 participants per group was calculated to provide sufficient power (at least $80 \%$ ) to detect this difference of $50 \%$ between the two groups at $5 \%$ level of significance.

\section{Statistical analyses}

\section{Demographics}

Using a Chi-square test, the binary presence or absence of the following discrete characteristics were compared between the control and study groups: sleep apnoea, sleeping difficulty, staying asleep difficulty, allergies, assistance with self-care needs, cancer diagnosis, current smoker, doing own shopping, difficulty falling asleep, former smoker, gender, immunosuppressant drugs, long COVID in the past, long COVID symptoms, major surgeries, mobility issues, non-prescribed or homoeopathic medications, organ transplant, other family history condition, physical activity, pregnancy weeks, prescribed medications. 
The following categorical increasing grades of pre-existing conditions were compared between both groups using a Chi-square test: "no vs mild/moderate/severity" (asthma, diabetes, high blood pressure, cholesterol, chronic obstructive pulmonary disease (COPD), cystic fibrosis, stroke). Due to the type of statistical analysis conducted, weight categories were compared "underweight/average" vs "obese", ethnicity categories were compared "white" vs "Asian/other", whilst the category "other", in gender demographics, was not considered during the calculations.

A Mann-Whitney U test $(\mathrm{p}<0.05)$ was performed, comparing the following characteristics: age, weight, height, smoking duration, time since quitting smoking and number of cigarettes smoked per day.

\section{PAC-19QoL QoLIs validation}

Using a Mann-Whitney test, statistically significant differences between the mean Likert score for each QoLI were compared between the responses from the study and control groups. A p-value $<0.05$ indicated a statistically significant finding in the presented analyses.

\section{Identification of PAC-19QoL QoLIs}

Using the Jandhyala Method, the PAC-19QoL indicators (QoLIs) were identified [13]. This is a novel way of observing proportional group awareness and consensus on answers arising from list-generating questioning. The method has been differentiated from competing consensus generating methodologies [14]. The participant consensus is achieved by observing levels of awareness and consensus relating to a list of recommended QoLIs for PAC-19QoL. These are solicited via two anonymised online surveys and calculating an awareness index $(\mathrm{Al})$ and consensus index $(\mathrm{Cl})$ for each item, respectively. The $\mathrm{Al}$ and $\mathrm{Cl}$, both continuous variables, were further categorised into $4 \mathrm{~A}$ and $\mathrm{C}$ scores.

During the first Awareness Round (1) survey, participants were asked to respond to the list-generating question: "Which areas of your lives do you (as post-acute COVID-19 patients) want to be included in a QoL measure for post-COVID-19 patients?". Participants were asked to provide a minimum of three, and a maximum of ten free-text answers.

The participants' responses from this Awareness Round (1) were analysed per group. They were then refined into mutually exclusive QoLIs by three researchers using a process of content analysis and open coding. The codes were then attributed to the relevant participants' answers by one researcher. They were then confirmed by a second.

The participants who completed the first round were asked to participate in the second, Consensus Round (2) survey. They were asked to rate their level of agreement with the inclusion of the QoLIs arising from the Awareness Round (1) survey. They were to use a five-point Likert-scale (Strongly agree, Agree, Neither agree nor disagree, Disagree and Strongly disagree). 
Quality of Life indicators reaching a consensus level of $>50 \%(\mathrm{Cl}>0.5)$ were retained in the final list and used to populate the PAC-19QoL.

\section{PAC-19QoL Validation}

The PAC-19QoL instrument was validated against a control group with 16 healthy individuals recruited from the networks of the researchers. Participant demographics were recorded for the study and control populations.

\section{Public and patient involvement}

Through our on-going work, we have established extensive networks with stakeholder groups and service users with rare diseases (such as XLH). In developing this project, we informally discussed the idea of developing a quality of life measure for people with a lived experience of COVID-19 with people within our extensive network. In total, the project idea was discussed with seven people, and each of these people expressed a need for a patient-centred Quality of Life measure that is easy to use and applicable to every aspect of their life, beyond the disease.

\section{Results}

\section{Generation of QoLls for inclusion in the PAC-19QoL instrument}

The study included 15 participants with long COVID-19 and saturation of unique QoLI's was achieved by participant 9 (Appendix).

Forty-nine unique QoLIs were generated during the Awareness Round (1) of the Jandhyala Method and grouped into the following four domains and 19 subdomains.

1. Psychological (Mood, Isolation, Motivation, Anxiety, Cognition, Expression, Mental Exertion),

2. Physical (Exertion, Pain, Travel, Somnolence, Smell/taste, Breathlessness, Fine motor, Libido),

3. Social (Isolation, Relationships, Hobbies), and

4. Work (Ability to work)

Anxiety (Psychological domain) and Exertion (Physical domain) were the two most-populated subdomains, containing 16.3\% (8/49) and 14.3\% (7/49) of QoLIs, respectively. Of the 49 QoLIs, 8 (16.3\%) displayed an $\mathrm{Al}>0.50$.

When the full list was presented to the participants in the Consensus Round (2), 48/49 (98\%) achieved a relative degree of prompting. Since 5 QoLIs failed to reach the cut-off point of $\mathrm{Cl}>0.50$, the remaining 44 QoLIs were included in PAC-19QoL. Validation of the PAC-19QoL instrument with regards to its specificity 
towards patients with long COVID showed that nine out of the 44 QoLIs failed to demonstrate a statistically significant difference between the study and control groups (Table 1 and Figure 1). The full list of 44 QoLIs was then converted to questions to populate the finalised PAC-19QoL.

Table 1. The 44 QoLls meeting threshold Cl>0.05 (CS:1\&2) included in the PAC-19QoL and the MannWhitney test of difference in Likert means for each item between the study and control populations. 


\begin{tabular}{|c|c|c|c|c|c|c|c|c|}
\hline \multirow[t]{2}{*}{ Domain } & \multirow[t]{2}{*}{ Subdomain } & \multirow[t]{2}{*}{ QoLI } & \multirow[t]{2}{*}{ QoLI Title } & \multicolumn{2}{|c|}{ Score } & \multicolumn{2}{|c|}{$\begin{array}{l}\text { Mean Likert } \\
\text { Score }\end{array}$} & \multirow[t]{2}{*}{ P-value } \\
\hline & & & & A & C & Control & Study & \\
\hline \multirow[t]{13}{*}{ Psychological } & Mood & $1 \dagger$ & $\begin{array}{l}\text { Feelings of low } \\
\text { mood (including } \\
\text { tearfulness) }\end{array}$ & 3 & 2 & 2.25 & 2.93 & 0.075 \\
\hline & & $2+$ & Feelings of anger & 3 & 2 & 1.88 & 2.53 & 0.065 \\
\hline & Isolation & 3 & $\begin{array}{l}\text { Feeling of being } \\
\text { isolated or lonely } \\
\text { due to the effects } \\
\text { of long COVID }\end{array}$ & 2 & 2 & 1.75 & 2.53 & $<0.05^{\star}$ \\
\hline & Motivation & 4 & $\begin{array}{l}\text { Motivation to } \\
\text { perform regular } \\
\text { activities }\end{array}$ & 3 & 2 & 2.00 & 2.73 & $<0.05^{\star}$ \\
\hline & Anxiety & 5 & $\begin{array}{l}\text { Anxious about the } \\
\text { future health of } \\
\text { myself }\end{array}$ & 3 & 2 & 1.94 & 3.73 & $<0.001^{*}$ \\
\hline & & 6 & $\begin{array}{l}\text { Anxious } \\
\text { specifically about } \\
\text { falling ill with } \\
\text { COVID-19 again. }\end{array}$ & 3 & 2 & 1.75 & 3.27 & $<0.05^{\star}$ \\
\hline & & $7 \dagger$ & $\begin{array}{l}\text { Anxious about the } \\
\text { future health of } \\
\text { my children }\end{array}$ & 3 & 2 & 2.13 & 2.27 & 0.693 \\
\hline & & 8 & $\begin{array}{l}\text { Anxious about the } \\
\text { future and the } \\
\text { quality of my } \\
\text { relationships with } \\
\text { my family }\end{array}$ & 3 & 2 & 2.13 & 3.07 & $<0.05^{\star}$ \\
\hline & & $9+$ & $\begin{array}{l}\text { Anxious about the } \\
\text { future and my } \\
\text { financial situation }\end{array}$ & 3 & 2 & 2.50 & 3.40 & 0.085 \\
\hline & & 10 & $\begin{array}{l}\text { Anxious about } \\
\text { being dependent } \\
\text { on or a burden to } \\
\text { relatives or others } \\
\text { (such as charities) }\end{array}$ & 3 & 2 & 1.56 & 2.80 & $<0.05^{\star}$ \\
\hline & & 11 & $\begin{array}{l}\text { Anxious about no } \\
\text { apparent reason }\end{array}$ & 3 & 2 & 1.69 & 3.33 & $<0.05^{\star}$ \\
\hline & & 12 & $\begin{array}{l}\text { Anxious about } \\
\text { experiencing } \\
\text { flashbacks of } \\
\text { traumatic events }\end{array}$ & 3 & 2 & 1.38 & 2.87 & $<0.05^{\star}$ \\
\hline & Cognition & 13 & $\begin{array}{l}\text { Ability to process } \\
\text { information and } \\
\text { organise thoughts }\end{array}$ & 2 & 2 & 1.75 & 3.00 & $<0.001^{*}$ \\
\hline
\end{tabular}




\begin{tabular}{|c|c|c|c|c|c|c|c|c|}
\hline & \multirow[b]{2}{*}{ Expression } & 14 & $\begin{array}{l}\text { Ability to } \\
\text { focus/concentrate } \\
\text { and perform } \\
\text { house chores }\end{array}$ & 3 & 2 & 1.94 & 2.87 & $<0.05^{\star}$ \\
\hline & & 15 & $\begin{array}{l}\text { Ability to express } \\
\text { oneself verbally }\end{array}$ & 3 & 2 & 1.69 & 3.00 & $<0.001$ * \\
\hline & $\begin{array}{l}\text { Mental } \\
\text { exertion }\end{array}$ & 16 & $\begin{array}{l}\text { Tiredness due to } \\
\text { mental exertion }\end{array}$ & 3 & 2 & 1.81 & 3.87 & $<0.001$ * \\
\hline & & 17 & $\begin{array}{l}\text { Mental exertion } \\
\text { triggers an } \\
\text { immediate } \\
\text { headache }\end{array}$ & 3 & 2 & 1.38 & 3.20 & $<0.001^{*}$ \\
\hline & & 18 & $\begin{array}{l}\text { Mental exertion } \\
\text { triggers post- } \\
\text { exertion malaise }\end{array}$ & 3 & 2 & 1.44 & 3.47 & $<0.001 *$ \\
\hline \multirow[t]{10}{*}{ Physical } & Exertion & 19 & $\begin{array}{l}\text { Exacerbation of } \\
\text { chest pain due to } \\
\text { physical exertion }\end{array}$ & 3 & 2 & 1.06 & 2.80 & $<0.05 \star$ \\
\hline & & 20 & $\begin{array}{l}\text { Exacerbation of } \\
\text { breathlessness } \\
\text { due to physical } \\
\text { exertion }\end{array}$ & 3 & 2 & 1.50 & 4.20 & $<0.001 *$ \\
\hline & & 21 & $\begin{array}{l}\text { Tiredness due to } \\
\text { physical exertion }\end{array}$ & 3 & 2 & 1.81 & 4.07 & $<0.001$ * \\
\hline & & 22 & $\begin{array}{l}\text { Impact in the } \\
\text { ability to perform } \\
\text { daily chores due } \\
\text { to exhaustion }\end{array}$ & 3 & 2 & 2.25 & 3.00 & $<0.05^{\star}$ \\
\hline & & 23 & $\begin{array}{l}\text { Impact on the } \\
\text { ability to } \\
\text { participate in } \\
\text { social events due } \\
\text { to exhaustion }\end{array}$ & 3 & 2 & 2.13 & 3.40 & $<0.001 *$ \\
\hline & & 24 & $\begin{array}{l}\text { Ability to look } \\
\text { after spouse or } \\
\text { children }\end{array}$ & 3 & 2 & 1.63 & 3.40 & $<0.001 *$ \\
\hline & & 25 & $\begin{array}{l}\text { Ability to wash } \\
\text { and dress }\end{array}$ & 3 & 2 & 1.50 & 2.40 & $<0.05^{\star}$ \\
\hline & Pain & $26+$ & Pain in joints & 3 & 2 & 1.81 & 2.00 & 0.71 \\
\hline & Travel & 27 & $\begin{array}{l}\text { Confidence in } \\
\text { ability to drive }\end{array}$ & 3 & 2 & 1.69 & 2.67 & $<0.05^{\star}$ \\
\hline & & $28+$ & $\begin{array}{l}\text { Ability to travel } \\
\text { using public or } \\
\text { transport }\end{array}$ & 3 & 2 & 2.44 & 2.93 & 0.066 \\
\hline
\end{tabular}




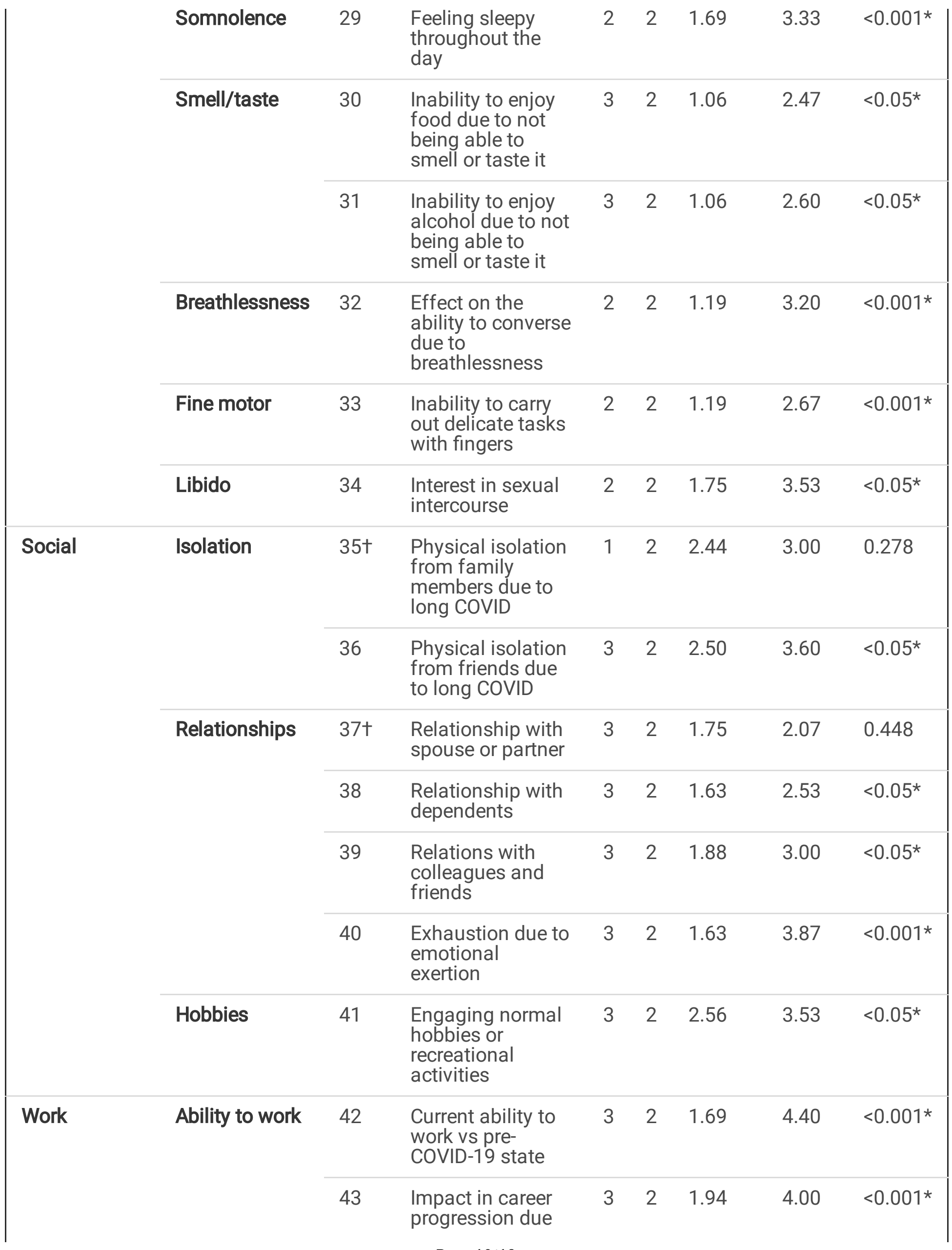

Page 10/19 
to being ill or on

sick leave

\begin{tabular}{lllllll}
$44 \dagger$ & $\begin{array}{l}\text { Loss of income } \\
\text { due to inability to } \\
\text { work }\end{array}$ & 3 & 2 & 2.06 & 3.00 & 0.14 \\
\hline
\end{tabular}

${ }^{+}$QoLls with no statistically significant differences between groups.

* Statistically significant at $95 \%$ confidence interval.

\section{Assessment of demographics}

For the development of the PAC-19QoL, 15 long COVID participants were recruited, four (27\%) and 11 (73\%) were male and female, respectively. The average age of the study and control groups were 40 and 35 respectively $(p=0.308)$. In order to validate the PAC-19QoL, 16 unaffected participants were recruited. Nine $(56 \%)$ of these were male, six (38\%) were female, and one (6\%) preferred not to say.

On assessing all baseline characteristics for heterogeneity, statistically significant differences were found between the two groups in the following demographics: long COVID symptoms $(p<0.001)$, COVID-19 in the past $(p<0.001)$, allergies $(p<0.05)$, asthma $(p=0.007)$, sleeping difficulty $(p=0.007)$, prescribed medications $(p<0.001)$ and dietary habits $(p<0.001)$. The study and control groups were comparable for all other demographic characteristics (Table 2).

Table 2. Demographic characteristics of both control and study groups in the study. 


\begin{tabular}{|c|c|c|c|}
\hline Characteristics & Control $(n=16)$ & Study $(n=15)$ & P-value \\
\hline Male (n (\%)) & $9(56)$ & $4(27)$ & \multirow[t]{3}{*}{0.113} \\
\hline Female (n (\%)) & $6(38)$ & 11(73) & \\
\hline Other (n (\%)) & $1(6)$ & $0(0)$ & \\
\hline Age (mean/years) & 35 & 40 & 0.308 \\
\hline Weight (mean/kg) & 68 & 74 & 0.170 \\
\hline Height (mean/cm) & 173 & 166 & 0.054 \\
\hline \multicolumn{4}{|l|}{ Ethnicity (n (\%)) } \\
\hline White & $9(56)$ & 11(73) & \multirow[t]{3}{*}{0.699} \\
\hline Asian & $3(19)$ & $1(7)$ & \\
\hline Other & $4(25)$ & $3(20)$ & \\
\hline \multicolumn{4}{|l|}{ Country (n (\%)) } \\
\hline UK & $3(19)$ & $9(60)$ & \\
\hline France & $1(6)$ & $0(0)$ & \\
\hline Portugal & $6(38)$ & $0(0)$ & \\
\hline India & $2(13)$ & $0(0)$ & \\
\hline Germany & $1(6)$ & $0(0)$ & \\
\hline Morocco & $3(19)$ & $3(20)$ & \\
\hline Canada & $0(0)$ & $1(7)$ & \\
\hline Ireland & $0(0)$ & $1(7)$ & \\
\hline Belgium & $0(0)$ & $1(7)$ & \\
\hline \multicolumn{4}{|l|}{ Medical History (n (\%)) } \\
\hline long COVID symptoms & $0(0)$ & 15(100) & $<0.001^{\star}$ \\
\hline COVID-19 in the past & $0(0)$ & $15(100)$ & $<0.001^{\star}$ \\
\hline Organ transplant & $0(0)$ & $0(0)$ & NA \\
\hline Major surgeries & $1(6)$ & $2(13)$ & 0.953 \\
\hline Cancer diagnosis & $0(0)$ & $0(0)$ & NA \\
\hline Cystic Fibrosis & $0(0)$ & $1(7)$ & 0.974 \\
\hline Asthma & $0(0)$ & $7(47)$ & $0.007^{\star}$ \\
\hline COPD & $0(0)$ & $0(0)$ & NA \\
\hline
\end{tabular}




\begin{tabular}{|c|c|c|c|}
\hline Diabetes: Type 1 & $0(0)$ & $0(0)$ & NA \\
\hline Diabetes: Type 2 & $6(38)$ & $0(0)$ & NA \\
\hline High Cholesterol & $1(6)$ & $2(13)$ & 0.436 \\
\hline High Blood Pressure & $0(0)$ & $2(13)$ & 0.953 \\
\hline Stroke & $0(0)$ & $0(0)$ & NA \\
\hline \multicolumn{4}{|l|}{ Family History (n (\%)) } \\
\hline Cystic Fibrosis (Family history) & $0(0)$ & $1(7)$ & 0.974 \\
\hline Asthma (Family history) & 2(13) & $3(20)$ & 0.937 \\
\hline COPD (Family history) & $0(0)$ & $2(13)$ & 0.436 \\
\hline Diabetes: Type 1 (Family history) & $0(0)$ & $1(7)$ & 0.974 \\
\hline Diabetes: Type 2 (Family history) & $6(38)$ & $2(13)$ & 0.260 \\
\hline High Cholesterol (Family history) & $2(13)$ & $5(33)$ & 0.587 \\
\hline High Blood Pressure (Family history) & $2(13)$ & $4(27)$ & 0.339 \\
\hline Stroke (Family history) & $2(13)$ & $3(20)$ & 0.937 \\
\hline \multicolumn{4}{|l|}{ Drug History (n (\%)) } \\
\hline Prescribed medications & $0(0)$ & 10(67) & $<0.001^{*}$ \\
\hline Non-prescribed or homoeopathic medications & $1(6)$ & $4(27)$ & 0.291 \\
\hline Immunosuppressant drugs & $0(0)$ & $1(7)$ & 0.974 \\
\hline Allergies & $2(13)$ & $8(53)$ & $0.041^{*}$ \\
\hline Pregnancy (n (\%)) & $0(0)$ & $0(0)$ & NA \\
\hline \multicolumn{4}{|l|}{ Social History (n (\%)) } \\
\hline Assistance with self-care needs & $0(0)$ & $1(7)$ & 0.974 \\
\hline Mobility issues & $0(0)$ & $1(7)$ & 0.974 \\
\hline Does own shopping & $16(100)$ & 12(80) & 0.203 \\
\hline Current smoker & 2(13) & $0(0)$ & 0.494 \\
\hline Former smoker & $4(25)$ & $3(20)$ & 0.499 \\
\hline Physical activity & $16(100)$ & 12(80) & 0.203 \\
\hline \multicolumn{4}{|l|}{ Sleep History (n (\%)) } \\
\hline Sleeping difficulty & $3(19)$ & $12(80)$ & $0.007^{\star}$ \\
\hline
\end{tabular}




\begin{tabular}{|lll|}
\hline Falling asleep difficulty & $3(19)$ & $7(47)$ \\
\hline Staying asleep difficulty & $2(13)$ & $9(60)$ \\
\hline Sleep apnoea & $2(13)$ & $3(20)$ \\
\hline Dietary habits $(\mathbf{n}(\%))$ & & \\
\hline Healthy & $2(13)$ & $12(80)$ \\
\hline Unhealthy & $14(88)$ & $3(20)$ \\
\hline Weight category (n (\%)) & & \\
\hline Underweight & $0(0)$ & $1(7)$ \\
\hline Average & $16(100)$ & $12(80)$ \\
\hline Overweight & $0(0)$ & $2(13)$ \\
\hline Employment $(\mathbf{n}(\%))$ & & \\
\hline Part time & $0(0)$ & $4(27)$ \\
\hline Full time & $13(81)$ & $6(40)$ \\
\hline Self-employed & $3(19)$ & $0(0)$ \\
\hline Unable to work & $0(0)$ & $1(7)$ \\
\hline Homemaker & $0(0)$ & $1(7)$ \\
\hline Student & $0(0)$ & $1(7)$ \\
\hline
\end{tabular}

* Statistically significant at 95\% confidence interval.

\section{Discussion}

\section{Findings}

Research into COVID-19 has preferentially focussed on symptomology, the acute nature of this illness and involved interventions such as therapeutics and vaccines. However, many patients display persistent symptoms with a continued impact on their quality of life weeks and months after the initial disease. Research on the impact of long COVID on quality of life is scarce and, until now, without a validated disease-specific instrument.

The PAC-19QoL instrument for the assessment of the quality of life in patients with long COVID was developed using the Jandhyala method to observe consensus on QoL indicators solicited in response to the questioning of recruited patients on how their long COVID affected their quality of life. It also provided an insight into the distribution of QoL indicators in their overall initial awareness among the study group and the final consensus. In this regard, 44/49 (89.98\%) indicators were observed to have been prompted from below the awareness threshold to above the consensus threshold and therefore deemed appropriate 
for inclusion in the PAC-19QoL. This high rate of prompting may reflect the limited ability of the participants to engage with the initial open-ended question due to the increased mental exertion involved in reviewing the areas of their life affected and then providing indicators. In contrast, the consensus round can be argued as a less intensive exercise with the subject being required to select a level of agreement on a pre-populated list. Understanding the intensely limiting impact long COVID has on cognition and mentation can help inform approaches to engaging with this patient population with information. Perhaps unsurprisingly, the most populated subdomains were: Psychological> Anxiety and Physical> Exertion. The latter, along with the Psychological> Mental Exertion subdomain, is consistent with the reporting of postexertional malaise in response to both physical and mental exertion by other researchers. The former brings into focus the specific concerns long COVID generates in its sufferers on their future. Finding of PTSD and idiopathic anxiety informs targets for supportive psychiatric, psychological interventions among a portfolio of multidisciplinary management strategies. The 44 QoLIs reaching the consensus threshold for inclusion in the final list of quality of life indicators were amenable to populating a questionnaire using basic 5-point Likert scales to assess the severity of each indicator at the time of administering.

On completion of its validation, the PAC-19QoL was implemented in the associated PAC-19QoLReg. This patient registry is currently recruiting and will observe a cohort of participants with long COVID, including those with a clinical diagnosis without a confirmed test, over a period of 12 months, with the PAC-19QoL being administering on a monthly basis. It offers the opportunity to track the QoL of the participants with long COVID beyond simple symptom monitoring, although any relapsing or remitting characteristics will add valuable knowledge to this emerging and debilitation disease.

\section{LIMITATIONS OF THE STUDY}

An initial challenge to the recruitment of subjects to this study was the requirement for a positive test to ensure the indicators generated could be reasonably attributed to long COVID. This requirement generated a degree of frustration in potential subjects, as a key concern around their initial management was the strict instructions of not presenting at their primary or secondary care facilities, thereby negating access to any form of testing.

A second potential limitation can be addressed by the fact that a number of QoLls failed to differentiate between the affected and non-affected individuals. These indicators perhaps infer broader concerns around long COVID not limited to sufferers. Furthermore, these may relate to the general impact of the restrictions imposed to control the spread of the virus, e.g., 'physical isolation from family members' and 'ability to use public transport'. QoLls such as 'low mood' and 'anger', 'anxiousness about future health of children' and 'future financial situation' are understandable concerns for anyone living through a global pandemic of a novel virus.

Debate over whether inclusion or exclusion of these QoLIs impacts the validity of the PAC-19QoL may ensue. Exclusion will remove any commonality of QoLIs between groups reducing a false-positive rate but also removing relevant QoLIs increases the false-negative rate. Given the overall proportion of these 9/44

Page 15/19 
$(20 \%)$ and the damaging effect of not detecting and following up an individual with long COVID, a reasonable justification can be made for retaining them. The numbers of participants included in the were sufficient to test univariate associations. However, studies with larger number of participants are required to test multivariable associations towards confirming these results.

\section{Conclusions And Implications}

It is hoped that the successful development and validation of the PAC-19QoL, a long COVID diseasespecific quality of life instrument and its implementation in the ongoing 12 month dedicated patient registry (PAC-19QoLReg) will complement ongoing research initiatives in monitoring long COVID QoL progression. It is also hoped that the development of the instrument will help to detect responses to therapeutic interventions with greater accuracy, ultimately informing patient care and improving outcomes.

\section{Declarations Funding}

The author received no funding for this particular work.

\section{Competing Interests Declaration}

The author is a visiting senior lecturer at the Centre for Pharmaceutical Medicine Research at Kings College London responsible for research into real-world evidence approaches.

The author is also the Founder and CEO of Medialis Ltd, a medical affairs consultancy and contract research organisation involved in the design and delivery of real-world evidence including the patient reported outcomes and patient registries.

Availability of data and material

Data from this study will be made available upon reasonable request to the author.

\section{Author Contributions}

RJ conducted the study and prepared, authored and approved the manuscript. The author also designed and implemented the patient registry. The author affirms that the manuscript is an honest, accurate, and transparent account of the study being reported; that no important aspects of the study have been omitted; any discrepancies from the study as planned (and, if relevant, registered) have been explained.

\section{Acknowledgements}


The author would like to acknowledge the contribution of Medialis personnel to the development of the PAC-19QoL instrument and the implementation of the PAC-19QoLReg.

\title{
Ethical Approval
}

The study was approved by the South West - Central Bristol Research Ethics Committee (IRAS 288729 Bristol SW REC).

\section{Consent to Participate}

All study participants provided written consent to participate in the study.

\section{Consent for Publication}

Not Applicable.

\section{Transparency Declaration}

Medialis continues to run the PAC-19QoLReg patient registry on behalf of the Centre for Pharmaceutical Medicine Research, Institute of Pharmaceutical Science, Faculty

of Life Science \& Medicine, King's College London, as part of its Corporate Social Responsibility Project.

\section{Abbreviations}

\author{
Al: Awareness Index \\ ARDS: Acute Respiratory Distress Syndrome \\ $\mathrm{Cl}$ : Consensus Index
}

COPD: Chronic Obstructive Pulmonary Disease

COVID-19: SARS-CoV-2 2019

PAC-19QoL: Post-Acute (long) COVID-19 Disease-Specific Quality of Life Instrument PAC-19QoLReg: Post-Acute (long) COVID-19 Disease-Specific Quality of Life Patient Registries QoL: Quality of Life

QoLI: Quality of Life Indicators

\section{References}

1. Cao X. COVID-19: immunopathology and its implications for therapy. Nature reviews immunology. 2020;20(5):269-70. doi:https://doi.org/10.1038/s41577-020-0308-3. 
2. Cucinotta D, Vanelli M. WHO Declares COVID-19 a Pandemic. Acta Biomed. 2020;91(1):157-60. doi:https://doi.org/10.23750/abm.v91i1.9397.

3. Velavan TP, Meyer CG. The COVID-19 epidemic. Tropical Medicine \& International Health. 2020;25(3):278-80. doi:https://doi.org/10.1111/tmi.13383.

4. Wang L, Wang Y, Ye D, Liu Q. Review of the 2019 novel coronavirus (SARS-CoV-2) based on current evidence. Int J Antimicrob Agents. 2020;55(6):105948-. doi:https://doi.org/10.1016/j.ijantimicag.2020.105948.

5. Meeting the challenge of long COVID. Nature Medicine. 2020;26(12):1803-. doi:https://doi.org/10.1038/s41591-020-01177-6.

6. Klok FA, Boon GJAM, Barco S, Endres M, Geelhoed JJM, Knauss S et al. The Post-COVID-19 Functional Status scale: a tool to measure functional status over time after COVID-19. European Respiratory Journal. 2020;56(1):2001494. doi:https://doi.org/10.1183/13993003.01494-2020.

7. Banerjee D. The COVID-19 outbreak: Crucial role the psychiatrists can play. Asian J Psychiatr. 2020;50:102014-. doi:https://doi.org/10.1016/j.ajp.2020.102014.

8. Bryson WJ. Long-term health-related quality of life concerns related to the COVID-19 pandemic: a call to action. Quality of Life Research. 2020. doi:https://doi.org/10.1007/s11136-020-02677-1.

9. Gibbon LM, GrayBuck KE, Buck LI, Huang K-N, Penumarthy NL, Wu S et al. Development and Implementation of a Clinician-Facing Prognostic Communication Tool for Patients With COVID-19 and Critical Illness. J Pain Symptom Manage. 2020;60(2):e1-e6.

doi:https://doi.org/10.1016/j.jpainsymman.2020.05.005.

10. Hill CL, Baird WO, Walters SJ. Quality of life in children and adolescents with Osteogenesis Imperfecta: a qualitative interview based study. Health and Quality of Life Outcomes. 2014;12(1):54. doi:https://doi.org/10.1186/1477-7525-12-54.

11. Guyatt GH, King DR, Feeny DH, Stubbing D, Goldstein RS. Generic and specific measurement of healthrelated quality of life in a clinical trial of respiratory rehabilitation. J Clin Epidemiol. 1999;52(3):187-92. doi:https://doi.org/10.1016/j10.1016/s0895-4356(98)00157-7.

12. Jandhyala R. Comment on: "Patient Registries: An Underused Resource for Medicines Evaluation: Operational Proposals for Increasing the Use of Patient Registries in Regulatory Assessments". Drug Safety. 2019;42(12):1515-6. doi:https://doi.org/10.1007/s40264-019-00862-x.

13. Jandhyala R. A novel method for observing proportional group awareness and consensus of items arising from list-generating questioning. Curr Med Res 2020;36(5):883-93. doi:https://doi.org/10.1080/03007995.2020.1734920.

14. Jandhyala R. Delphi, non-RAND modified Delphi, RAND/UCLA appropriateness method and a novel group awareness and consensus methodology for consensus measurement: a systematic literature review. Curr Med Res. 2020:1-15. doi:https://doi.org/10.1080/03007995.2020.1816946.

\section{Figures}




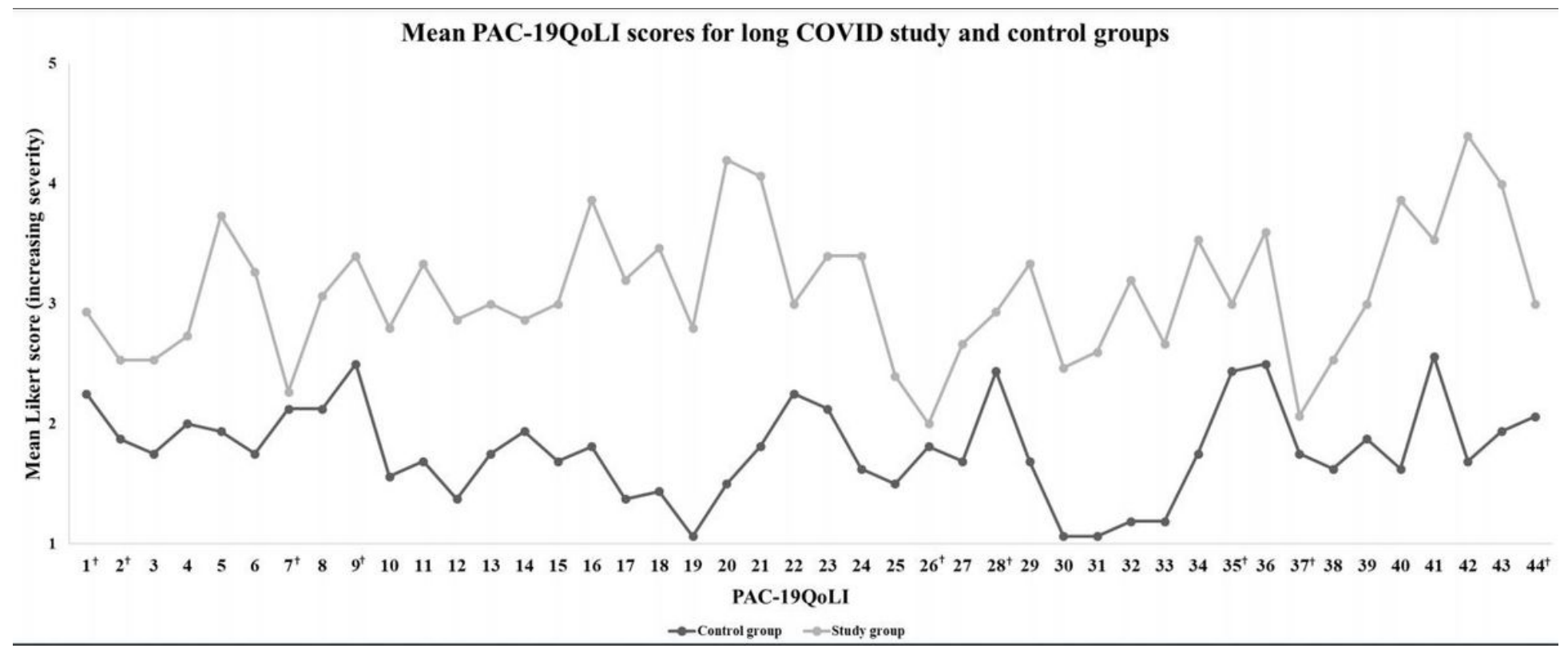

Figure 1

PAC-19QoLI Likert scores for control and study groups. † QoLIs with no statistically significant differences between groups.

\section{Supplementary Files}

This is a list of supplementary files associated with this preprint. Click to download.

- Appendix.pdf 